\title{
Ozonation of Ethinylestradiol in Aqueous-Methanolic Solution: Direct Monitoring by Electrospray Ionization Mass Spectrometry
}

\author{
Karla M. Vieira, Clésia C. Nascentes and Rodinei Augusti* \\ Departamento de Química, Instituto de Ciências Exatas, Universidade Federal de Minas Gerais, \\ 31270-901 Belo Horizonte-MG, Brazil
}

\begin{abstract}
A ozonólise do etinilestradiol (1), um hormônio sintético esteroidal, numa solução de água/metanol foi investigada. Análises por HPLC-UV revelaram que o hormônio foi completamente consumido, tanto em pH 5 quanto 8, após um tempo reacional de $20 \mathrm{~min}$. O monitoramento por espectrometria de massas com ionização electrospray no modo negativo (ESI(-)-MS) revelou o contínuo consumo de $\mathbf{1}$ (detectado em sua forma desprotonada, [1 - H] $]^{-}$, de $\mathrm{m} / \mathrm{z}, 295$ ), concomitantemente com o aparecimento de produtos de oxidação. Estruturas químicas foram propostas para tais produtos com base nos dados de MS (valores de $m / z$ ) e MS/MS (padrões de fragmentação dos ânions). Estes dados, em associação com conhecimento sobre a reatividade de moléculas orgânicas frente ao ozônio em solução aquosa, foram avaliados e uma rota reacional inédita para a ozonização do etinilestradiol foi sugerida. Assim, como primeira etapa nesta sequência reacional propôs-se uma adição 1,3-dipolar do ozônio sobre o anel fenólico de $\mathbf{1}$ para gerar o produto di-hidroxilado 2 (detectado como $[2-\mathrm{H}]^{-}$de $\mathrm{m} / \mathrm{z} 3311$ ). A perda de acetileno como o único canal de dissociação de $[\mathbf{2}-\mathrm{H}]^{-}$confirmou que a hidroxilação ocorreu no anel fenólico e não na porção acetilênica de $\mathbf{1}$. Oxidações subsequentes foram propostas para explicar a formação de outros produtos, todos eles contendo o grupo funcional $\mathrm{COOH}$ (como verificado pela dissociação das respectivas moléculas desprotonadas através da perda característica de $\mathrm{CO}_{2}$ ). Os dados de ESI(-)-MS também revelaram diferenças notáveis entre as reações conduzidas em pH 5 e 8, i.e., em meios levemente ácido e básico, respectivamente.
\end{abstract}

The ozonolysis of ethinylestradiol (1), a synthetic steroidal estrogen, in an aqueous-methanolic solution was investigated. HPLC-UV analyses revealed that $\mathbf{1}$ was completely consumed after a 20 min reaction time either at $\mathrm{pH} 5$ or 8 . ESI(-)-MS (electrospray ionization mass spectrometry in the negative ion mode) monitoring also revealed the continuous consumption of $\mathbf{1}$ (detected as $[\mathbf{1}-\mathrm{H}]^{-}$of $\mathrm{m} / \mathrm{z} 295$ ) concomitantly with the emergence of oxidation products. Chemical structures were proposed for these products based on the data of MS and MS/MS (the $m / z$ values and fragmentation profiles of the anionic specie, respectively). These data, in conjunction with the well-established knowledge about the reactivity of organic molecules toward ozone in aqueous solution, were evaluated and an unprecedented reaction route for the ozonation of $\mathbf{1}$ could thus be suggested. Hence, the first step in this reaction sequence was ascribed to involve a 1,3-dipolar cycloaddition of ozone at the phenolic ring of $\mathbf{1}$ yielding the di-hydroxylated product $\mathbf{2}$ (detected as $[2-\mathrm{H}]^{-}$of $\left.m / z 311\right)$. The loss of acetylene as the unique dissociation channel for $[2-\mathrm{H}]^{-}$thus confirmed that such hydroxylation occurred at the phenolic ring rather than the acetylenic moiety of 1. Subsequent oxidations were proposed to be the origin of a number of other products, all of them bearing the $\mathrm{COOH}$ functionally (this was verified by the characteristic loss of $\mathrm{CO}_{2}$ during the dissociation of the related deprotonated molecules). The ESI(-)-MS records also revealed notable differences between the reaction conducted at $\mathrm{pH} 5$ and 8, i.e. at slightly acid or basic media, respectively.

Keywords: ethinylestradiol, degradation, ozone, reaction monitoring, direct infusion, electrospray ionization, mass spectrometry

*e-mail: augusti@ufmg.br 


\section{Introduction}

Ethinylestradiol (1, Figure 1), a synthetic steroidal estrogen, is a common component widely used as the active principle of many contraceptive agents and therapy drugs. ${ }^{1,2}$ The occurrence of estrogen hormones in natural systems, such as surface waters, soils and sediments, has becoming a subject of major concern. ${ }^{3}$ There are many sources of the so-called estrogenic pollution including effluents from municipal and industrial wastewater treatment plants, livestock wastes, biosolids, septic tanks and landfills. ${ }^{4}$ Many problems have been related to the existence of these hormones in natural waters, for instance feminization of male fishes, ${ }^{5-8}$ the lower sperm counts in adult males and an increasing incidence of cancer.-14 In addition, the conventional treatment procedures usually employed in wastewater plants are not capable to completely remove such compounds from the water that is directly supplied to the population. ${ }^{4,13,15,16}$

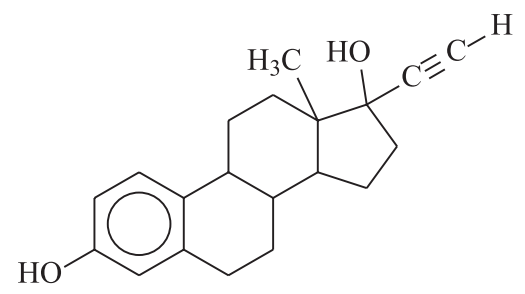

Figure 1. Chemical structure of the synthetic hormone ethinylestradiol (1)

Owing to an increasing awareness regarding the potential risks associated with the release of hormones (and other persistent pollutants) directly into the environment, the development of effective treatment technologies to promote their degradation has becoming a matter of significant importance ${ }^{3,17,18}$ For instance, oxidation processes, which usually include the use of ozone, chlorine and chlorine dioxide as effective oxidants, have been widely applied in treatment facilities not only for disinfection of wastewaters but also for elimination of undesired micropollutants from drinking water. ${ }^{3,11,17,19}$ Among these processes, ozonation has attracted the foremost attention as ozone has shown to be a conveniently cheap, clean and powerful oxidant. As a consequence, ozone has been successfully applied to remediate several contaminated effluents ${ }^{20-22}$ and has been used as an environmental friendly oxidation agent in many fields. ${ }^{23,24}$

Electrospray ionization (ESI) is well-recognized to have a remarkable capability to gently transfer ionic species from the condensed to the gas phase, usually with no substantial in-source fragmentation. ${ }^{25,26}$ Most important, it has been verified that the composition of the ESI-generated ions are closely related to that of the solution. ${ }^{27-29}$ Electrospray ionization mass spectrometry (ESI-MS), because of its appealing and unique attributes, has rapidly becoming an alternative approach suitably employed to a direct monitoring of a increasing number of relevant environmental processes. ${ }^{30-40}$ In these inquiries, the information provided by the MS (the $\mathrm{m} / \mathrm{z}$ values of the ionic species) and MS/MS data (the fragmentation profiles of a given mass-selected ion) are meticulously evaluated aiming to propose chemical structures of products (and in some cases transient intermediates) likely formed in the condensed phase. ${ }^{41}$

The identification of by-products arising from oxidative treatments, which can be more risky than the own precursors indeed,,$^{42}$ is an important point that must be taken into consideration for the evaluation of the overall performance of a given process. Therefore, several studies have been conducted aiming to identify products formed by the ozonation of ethinylestradiol (1) in aqueous medium. For instance, Huber and coworkers ${ }^{18}$ made use of LC-MS/MS and GC-MS techniques to identify the products formed in the reaction of ozone with two model compounds (bearing the same characteristic functional groups than 1, i.e., the phenolic ring and the acetylenic moiety, see Figure 1). Based on these experimental results, the authors were thus able to propose chemical structures for possible products arising from the ozonation of $\mathbf{1}$. In an analogous report, ${ }^{43}$ HPLC and GC-MS data showed that $\mathbf{1}$ reacts with ozone to yield a number of organic acids, such as malonate and glutarate, which were easily oxidized further into carbon dioxide. More recently, Dezotti and coworkers ${ }^{44}$ performed a systematic investigation on the reduction of the estrogenic activity of aqueous solutions of $\mathbf{1}$ submitted to ozonation. In addition to these studies, the authors were able to identify, via GC-MS analysis of derivatized samples, products arising from hydroxylation at the phenolic ring of $\mathbf{1}$.

In this work, direct infusion electrospray ionization mass and tandem mass spectrometry (ESI-MS and ESI-MS/ MS, respectively) are employed to monitor the ozonation of $\mathbf{1}$ in an aqueous-methanolic solution. A very low ozone flow rate is used aiming to detect and characterize transient products formed under these mild conditions before their complete depletion. Based on these experimental data, and also on the well-known reactivity of ozone toward organic molecules in water medium, a plausible reaction route for the degradation of ethinylestradiol (1) by ozone is proposed. High performance liquid chromatography (HPLC) is also utilized as an auxiliary technique to verify whether the substrate degradation can yield residual organic compounds in solution. 


\section{Experimental}

\section{Chemicals}

Ethinylestradiol (98\% purity, Organon, São Paulo, Brazil) and HPLC-grade acetonitrile and methanol (Vetec, São Paulo, Brazil) were used as received. Milli-Q water was utilized to prepare all the solutions required. Ozone was produced by a generator (Eletro-Triozon, Brazil) fed with synthetic air. The ozone flow rate, determined by the iodometry titration method, was $20 \mu \mathrm{mol} \mathrm{min}{ }^{-1}$.

\section{Ozonation}

Because of the very low solubility of $\mathbf{1}$ in pure water, a mixture of methanol/water (3:7 v/v) was used as solvent in all the experiments. Methanol is a convenient solvent as it is completely miscible in water and has a very low reactivity toward ozone. ${ }^{45}$ Hence, to a solution of $\mathbf{1}$ (100 $\mathrm{mg} \mathrm{L}^{-1}, 338 \mu \mathrm{mol} \mathrm{L}{ }^{-1}$ ) in methanol/water 3:7 v/v $(20 \mathrm{~mL}$ ), at pH 5 (the natural $\mathrm{pH}$ of such solution) or 8 (achieved by the addition of $\mathrm{NH}_{4} \mathrm{OH} 1 \mathrm{~mol} \mathrm{~L}^{-1}$ ), an ozone/ air gas stream was continuously bubbled. Aliquots of the reaction solution were withdrawn at assorted times and immediately analyzed.

\section{Analytical methods}

\section{$H P L C-U V$}

Chromatographic separation was performed in an SPD-M10A VP instrument (Shimadzu, Kyoto, Japan) using a Hypersil C18 column (250 mm long, $4.6 \mathrm{~mm}$ i.d., $5 \mu \mathrm{m}$ particle size) and acetonitrile/ $\mathrm{H}_{2} \mathrm{O}(2: 3)$ as mobile phase. The isocratic elution was maintained at a flow rate of $1 \mathrm{~mL} \mathrm{~min}-1$ for a $10 \mathrm{~min}$ chromatographic run. The injection volume was of $20 \mu \mathrm{L}$ and UV detection carried out at 210 and $280 \mathrm{~nm}$.

\section{ESI-MS and ESI-MS ${ }^{n}$}

The analyses were conducted in a LCQFleet (ThermoScientific, San Jose, CA) mass spectrometer bearing an electrospray ionization (ESI) source and operating in the negative ion mode. Mass spectra were obtained as an average of 50 scans, each one requiring $0.2 \mathrm{~s}$. The aliquots were directly infused into the ESI source at a flow rate of $25 \mu \mathrm{L} \mathrm{min}{ }^{-1}$ by means of a $500 \mu \mathrm{L}$ microsyringe (Hamilton, Reno, NV). ESI source conditions were as follows: heated capillary temperature of $285^{\circ} \mathrm{C}$, sheath gas $\left(\mathrm{N}_{2}\right)$ flow rate at 20 (arbitrary units), spray voltage of $5.0 \mathrm{kV}$, capillary voltage of $-38 \mathrm{~V}$, tube lens offset voltage of $-110 \mathrm{~V}$. For the ESI-MS/MS experiments, the precursor ions were first isolated within the ion trap and then resonantly dissociated via collision-induced dissociation (CID) using helium as the target gas. The relative collision energy was set to a value at which the product ions were produced in measurable abundance (varying from 18 to $40 \%$ ). The isolation width used in the MS/MS experiments was $2 \mathrm{~m} / \mathrm{z}$ units.

\section{Results and Discussion}

\section{Ozonation of ethynilestradiol (1): HPLC monitoring}

Firstly, results from control experiments (aqueousmethanolic solutions of ethynilestradiol continuously bubbled with air) demonstrated that the hormone was not consumed at all by molecular oxygen. To verify the rate of consumption of $\mathbf{1}$ by ozone in an aqueous-methanolic solution (at pH 5), as well as the formation of degradation products, the reaction was monitored by HPLC-UV. The chromatograms of the initial solution and aliquots withdrawn after assorted times are shown in Figure 2. Note that the intensity of the peak related to compound 1 (retention time of $c a .7 \mathrm{~min}$ ) decreased whereas other peaks appeared continuously at shorter retention times. These data thus indicate that degradation products, likely with higher polarity than $\mathbf{1}$ as they eluted faster from the non-polar (C18) chromatographic column, were formed in this medium. ${ }^{46}$ In addition, the peak related to precursor $\mathbf{1}$ greatly decreased after $20 \mathrm{~min}$. At last, similar HPLC data regarding the ozonation of $\mathbf{1}$ in an aqueous medium were achieved in previously-reported studies. .,10,17,20 $^{2}$

\section{ESI-MS monitoring and ESI-MS ${ }^{n}$ structural evaluation}

Figure 3 displays representative ESI mass spectra in the negative ion mode, ESI(-)-MS, of an aqueous-methanolic solution of ethinylestradiol (1) obtained after 0, 20, $100 \mathrm{~min}$ of ozone bubbling. The mass spectra in the positive ion mode (not shown) were also gathered but the results were not as clarifying as in the negative ion mode. Because of that, only the ESI(-)-MS are presented herein. Hence, in Figure 3a, which displays the ESI(-)-MS of the initial solution of 1 at $100 \mathrm{mg} \mathrm{L}^{-1}$, an intense and prominent ion of $\mathrm{m} / z$ 295, corresponding to $[\mathbf{1}-\mathrm{H}]^{-}$(the deprotonated form of $\mathbf{1}$ ), is observed. Its mass-selection and fragmentation upon collision-induced dissociation (CID) yielded a product ion of $\mathrm{m} / \mathrm{z} 269$ (not shown) formed via acetylene loss. Note that the relative intensity of the ion $[\mathbf{1}-\mathrm{H}]^{-}$decreased considerably as the reaction proceeded whereas new and intense anions of $m / z, 301,311,325,335,343,359,375$ emerged continuously and concomitantly (Figures $3 \mathrm{~b}$ and $3 \mathrm{c}$ ). 


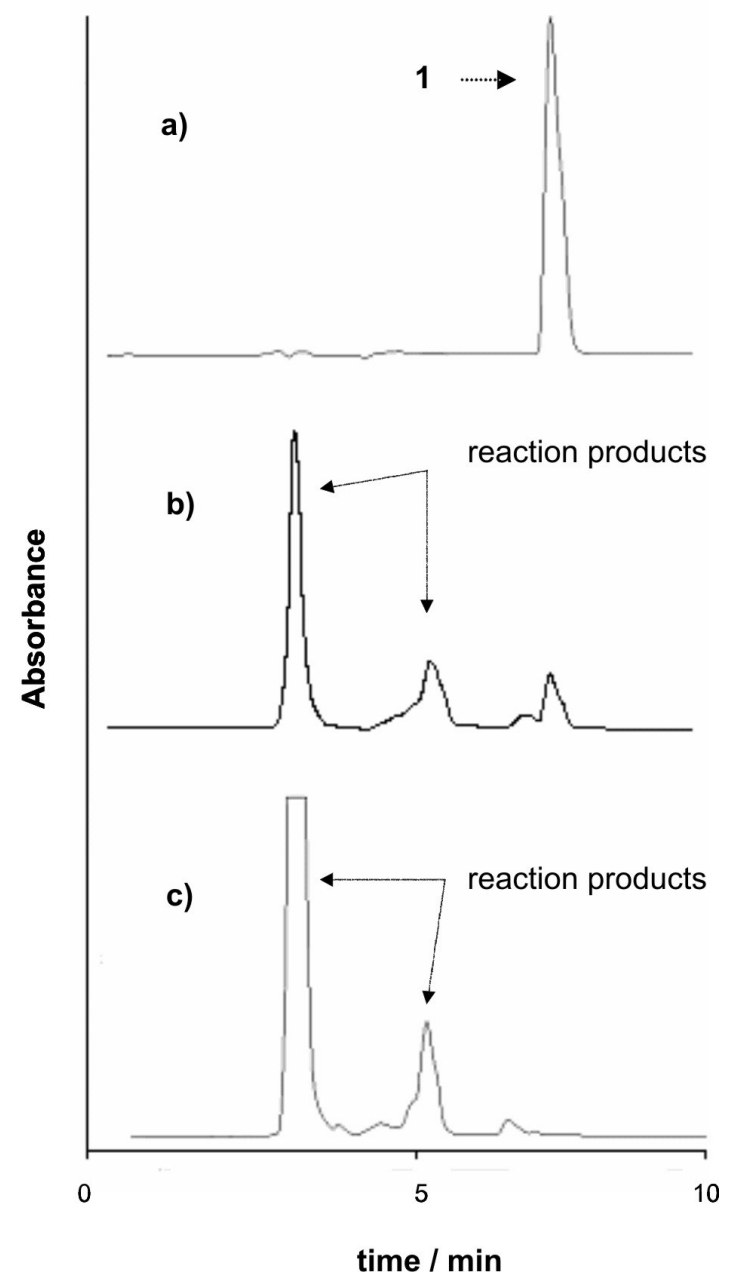

Figure 2. HPLC-UV (210 nm) chromatograms of the initial solution of $\mathbf{1}$ (a) and of aliquots taken after different times of ozonation: (b) $20 \mathrm{~min}$; (c) 100 $\min$. Note the appearance of new chromatographic peaks with retention times shorter than that of $\mathbf{1}$.

These data thus indicated a continuous consumption of $\mathbf{1}$, as also verified in the previously described HPLC-UV data, with the concomitant formation of oxidation products.

As represented in Scheme 1, product 2, detected in its deprotonated form of $m / z 311$, was proposed to be formed via a hydroxylation at the position 2 of the phenolic ring of $\mathbf{1}$. In a previous report, ${ }^{43}$ compound $\mathbf{2}$ was identified as one of the initial products resulting from the ozonation of $\mathbf{1}$ in aqueous medium. In this reaction pathway, the ozone attack was proposed to occur exclusively at the phenolic ring of $\mathbf{1}$ as its second reactive group, the ethynil substituent, exhibits a considerably lower reactivity toward $\mathrm{O}_{3} \cdot{ }^{18}$ This assumption was confirmed by the fragmentation of $[2-\mathrm{H}]^{-}$which yielded an intense product ion of $\mathrm{m} / \mathrm{z} 285$ arising from the loss of acetylene (Figure 4). Moreover, on the basis of previous studies ${ }^{18,47}$ other isomers of $\mathbf{2}$, with the second hydroxyl group connected at positions 1 and 4 of the phenolic ring of $\mathbf{1}$, were also possibly formed.

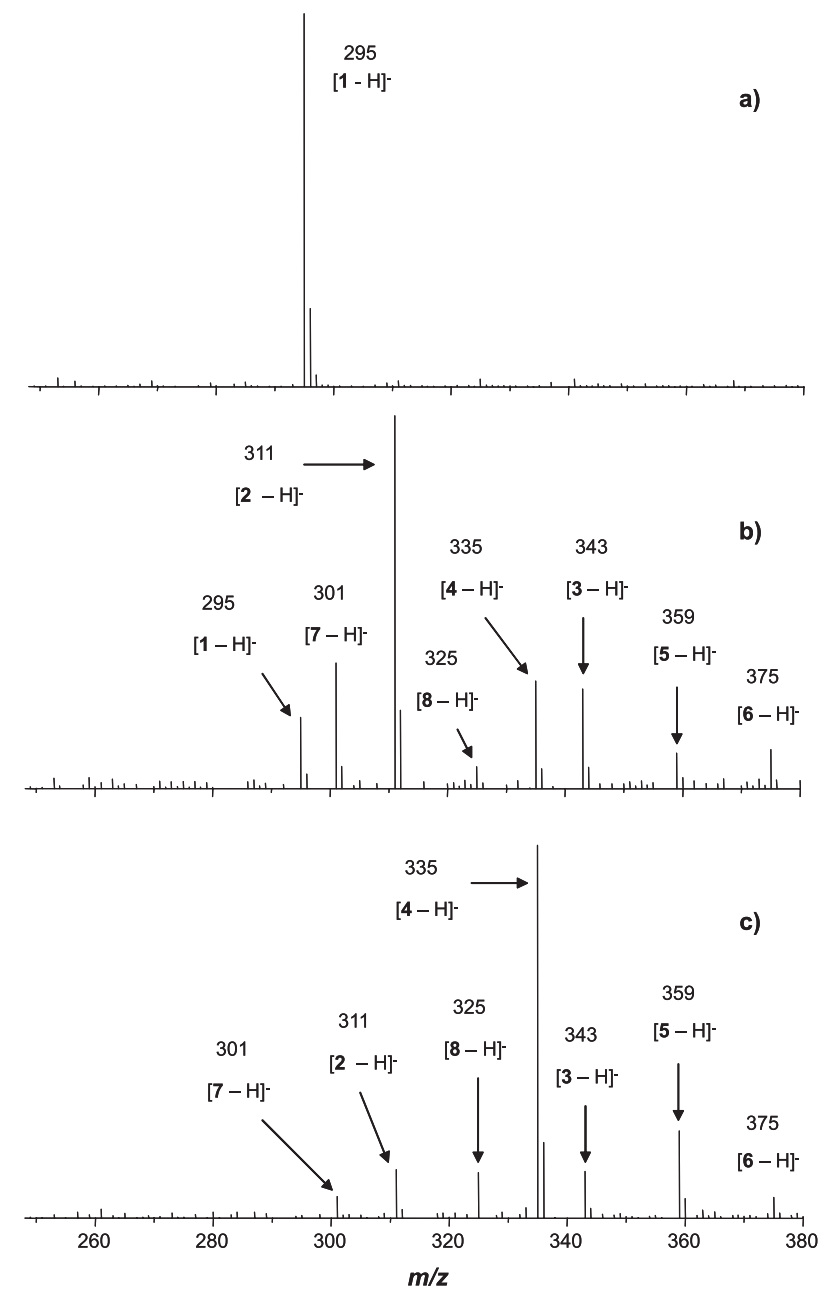

Figure 3. ESI(-)-MS monitoring of the ozonation of ethinylestradiol (1) conducted in an aqueous-methanolic solution at $\mathrm{pH}$ 5. Aliquots were collected at the following reaction times: (a) $0 \mathrm{~min}$; (b) $20 \mathrm{~min}$; (c) $100 \mathrm{~min}$.

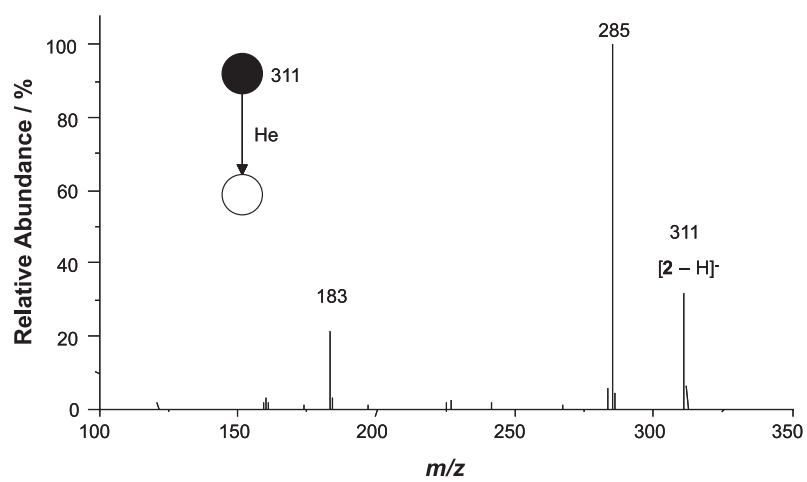

Figure 4. ESI tandem mass spectra (MS/MS) of the anion $[2-\mathrm{H}]^{-}$of $\mathrm{m} / \mathrm{z} 311$.

The hydroxylated compound $\mathbf{2}$ (and its positional isomers), which has a high reactivity toward $\mathrm{O}_{3}$ than the own precursor 1, could be quickly oxidized further to yield an unstable quinone-type intermediate ${ }^{11}$ (not shown in Scheme 1) that underwent sequential oxidation and 
ring cleavage $\mathrm{e}^{48,49}$ to produce the muconic acid derivative $\mathbf{3}$ (detected as $[\mathbf{3}-\mathrm{H}]^{-}$of $m / z$ 343, Figure 3).

From intermediate 3 a number of ensuing transformations (Scheme 1) were proposed to take place. Hence, 3 was oxidized further to yield 4 (detected as $[4-\mathrm{H}]^{-}$of $m / z$, 335, Figure 3) via the release of four molecules of $\mathrm{H}_{2}$. The driving force of such conversion, certainly induced by ozone (a strong oxidizing agent), was probably the formation of an
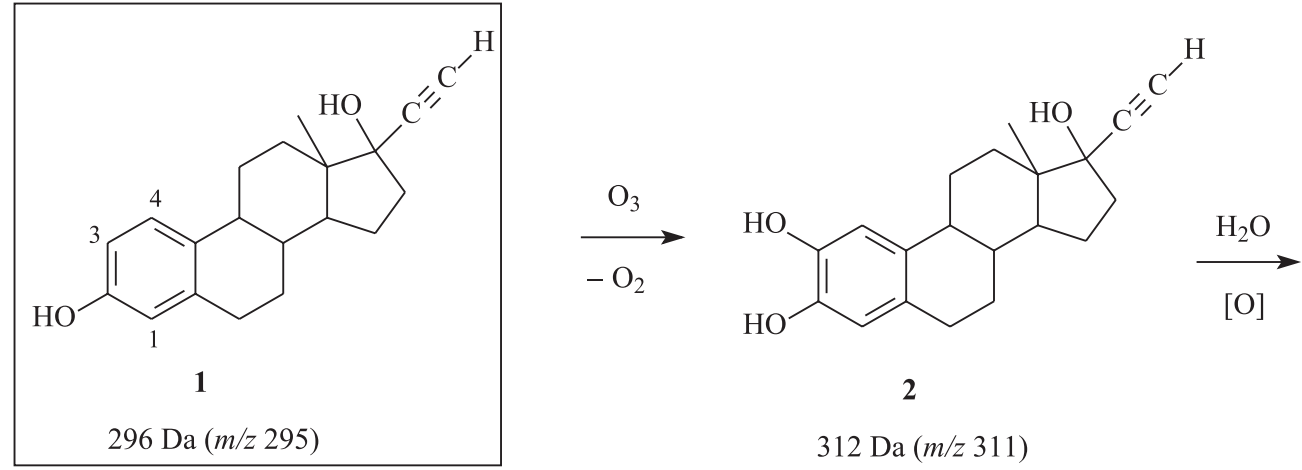

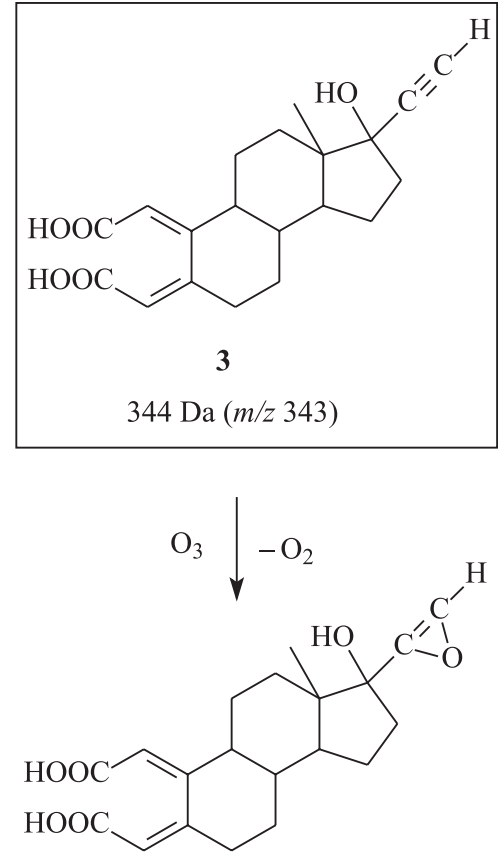

5

$360 \mathrm{Da}(\mathrm{m} / \mathrm{z} 359)$

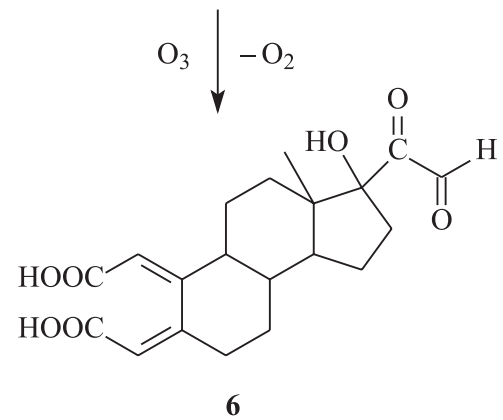

$376 \mathrm{Da}(\mathrm{m} / \mathrm{z} 375)$

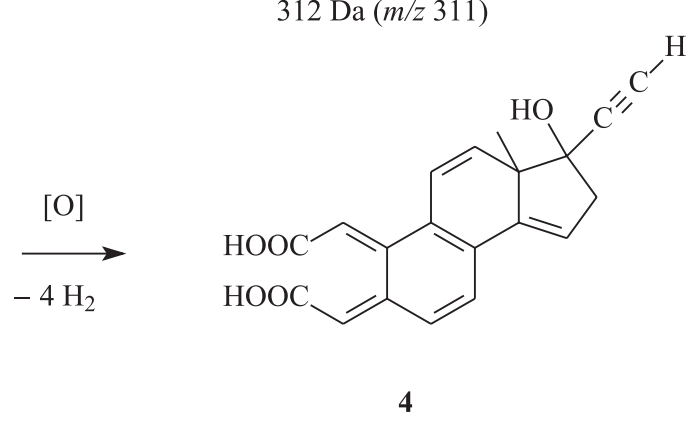

$336 \mathrm{Da}(\mathrm{m} / \mathrm{z} 335)$
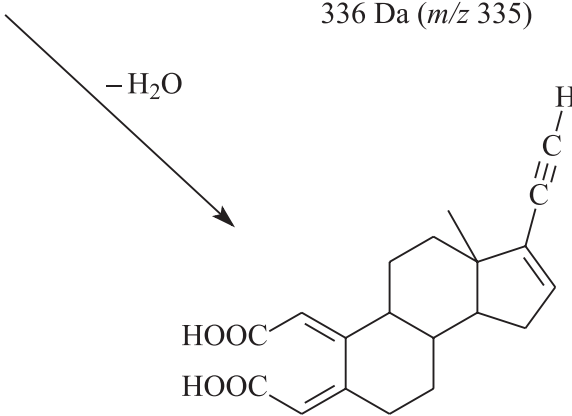

8

$326 \mathrm{Da}(\mathrm{m} / \mathrm{z} 325)$

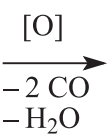

Scheme 1. Reaction pathways proposed for the reaction of ethinylestradiol (1) with ozone in an aqueous-methanolic solution at $\mathrm{pH}$ 5. Ions quoted under the structures are those detected by ESI(-)-MS. Note that the initial $\mathrm{O}_{3}$ attack at the position 3 of the phenolic ring of $\mathbf{1}$ lead to the formation of product $\mathbf{2}$. $\mathrm{O}_{3}$ could also attack at positions 1 and 4 of such ring but the structures of the resulting products (positional isomers of 2 ) are not displayed herein. 
extensive $\pi$-electron conjugation system that surely play a role in the stabilization of compound 4 . Actually, it has been reported that stabilized compounds (with similar conjugated systems than 4) can be promptly formed via dehydrogenation processes promoted by oxidizing agents, such as molecular oxygen and ozone. ${ }^{50}$ In an parallel pathway, it was proposed that $\mathbf{3}$ could react with $\mathrm{O}_{3}$ to yield the epoxide $\mathbf{5}$ (detected as $[5-\mathrm{H}]^{-}$of $m / z 359$, Figure 3). Such process probably proceeded via the well-known Crigee mechanism, ${ }^{51}$ which postulates that the attack of $\mathrm{O}_{3}$ on the (available) ethinyl moiety of $\mathbf{3}$ could result in the formation of a primary ozonide (not shown in Scheme 1) that could quickly decompose to yield 5. Following this reactional sequence, it was plausibly suggested that ozone could react at the carbon-carbon double bond of the epoxide ring of $\mathbf{5}$, probably via the Crigee mechanism, to yield the aldehyde $\mathbf{6}$ (detected as its deprotonated form of $m / z, 375$, Figure 3). Compound $\mathbf{6}$ could then undergo further oxidation and subsequent elimination of 2 molecules of $\mathrm{CO}$ and $\mathrm{H}_{2} \mathrm{O}$ to yield product 7 (detected as $[7-\mathrm{H}]^{-}$of $m / z$ 301, Figure 3). Finally, intermediate 3 could undergo loss of water to yield product $\mathbf{8}$ (detected as $[8-\mathrm{H}]^{-}$of $m / z$ 325, Figure 3).

The mass-selection and fragmentation of the abovementioned anions, i.e., $[3-\mathrm{H}]^{-},[4-\mathrm{H}]^{-},[5-\mathrm{H}]^{-},[6-\mathrm{H}]^{-}$, $[7-\mathrm{H}]^{-}$, and $[8-\mathrm{H}]^{-}$, yielded product ions arising mainly from loss of $\mathrm{CO}_{2}(44 \mathrm{Da})$ and other small molecules (Table 1). These data are thus consistent with the proposed structures for the reaction products since all of them bear the $\mathrm{COOH}$ functionality and the loss of $\mathrm{CO}_{2}$ is a very characteristic dissociation channel for carboxylates. ${ }^{52}$

In Figure 5, the fraction of each anion, i.e., $[1-\mathrm{H}]^{-}$, $[2-\mathrm{H}]^{-},[3-\mathrm{H}]^{-},[4-\mathrm{H}]^{-},[5-\mathrm{H}]^{-},[6-\mathrm{H}]^{-},[7-\mathrm{H}]^{-}$ and $[8-\mathrm{H}]^{-}$, is plotted against the reaction time. These

Table 1. Main product ions arising from the dissociation of the anions $[3-\mathrm{H}]^{-},[4-\mathrm{H}]^{-},[5-\mathrm{H}]^{-},[6-\mathrm{H}]^{-},[7-\mathrm{H}]^{-}$and $[8-\mathrm{H}]^{-}$detected in the ESI(-)-MS of an aqueous-methanolic solution of ethinylestradiol (1) submitted to an ozone stream

\begin{tabular}{ll}
\hline Precursor ion $(\mathrm{m} / \mathrm{z})$ & Product ions $(\mathrm{m} / z$; relative abundance \%) \\
\hline$[\mathbf{3}-\mathrm{H}]^{-}(343)$ & {$\left[\mathbf{3}-\mathrm{H}-\mathrm{CO}_{2}\right]^{-}(299 ; 100)$} \\
& {$\left[\mathbf{3}-\mathrm{H}-\mathrm{H}_{2} \mathrm{O}\right]^{-}(325 ; 10)$} \\
& {$\left[\mathbf{3}-\mathrm{H}-\mathrm{C}_{2} \mathrm{H}_{2}\right]^{-}(317 ; 7)$} \\
& {$\left[\mathbf{4}-\mathrm{H}-\mathrm{CO}_{2}\right]^{-}(291 ; 100)$} \\
{$[\mathbf{4}-\mathrm{H}]^{-}(335)$} & {$\left[\mathbf{4}-\mathrm{H}-\mathrm{H}_{2} \mathrm{O}\right]^{-}(317 ; 40)$} \\
{$[\mathbf{5}-\mathrm{H}]^{-}(359)$} & {$\left[\mathbf{5}-\mathrm{H}-\mathrm{CO}_{2}\right]^{-}(315 ; 100)$} \\
{$[\mathbf{6}-\mathrm{H}]^{-}(375)$} & {$\left[\mathbf{5}-\mathrm{H}-\mathrm{H}_{2} \mathrm{O}\right]^{-}(341 ; 20)$} \\
& {$\left[\mathbf{6}-\mathrm{H}-\mathrm{CO}_{2}\right]^{-}(331 ; 100)$} \\
{$[\mathbf{7}-\mathrm{H}]^{-}(301)$} & {$\left[\mathbf{6}-\mathrm{H}-\mathrm{H}_{2} \mathrm{O}\right]^{-}(357 ; 30)$} \\
{$[\mathbf{8}-\mathrm{H}]^{-}(325)$} & {$\left[\mathbf{7}-\mathrm{H}-\mathrm{CO}_{2}\right]^{-}(257 ; 100)$} \\
\hline
\end{tabular}

fractions, obtained as the ratio between the absolute intensity of a given ion and the sum of the absolute intensities of the whole set of ions as measured from a certain mass spectrum, comprise a convenient approach to monitor the changes in the relative concentrations of compounds $\mathbf{1 - 8}$ as the reaction proceeded. Hence, these results revealed that after $20 \mathrm{~min}$ reaction time a notable degradation of $\mathbf{1}$ was achieved (a similar finding was accomplished by the HPLC-UV data as indicated in Figure 2). Note also that compound 2 reached its maximum relative concentration at roughly $20 \mathrm{~min}$ and decreased afterwards. Furthermore, product 4 was found to be predominant after 100 min reaction time which possibly denotes its superior resistance towards ozone attack in comparison to the other products. Finally, the relative concentration of the other compounds $(\mathbf{3}, \mathbf{5}$, 6, 7 and 8) experienced smaller (but perceptible) changes during the reaction course.

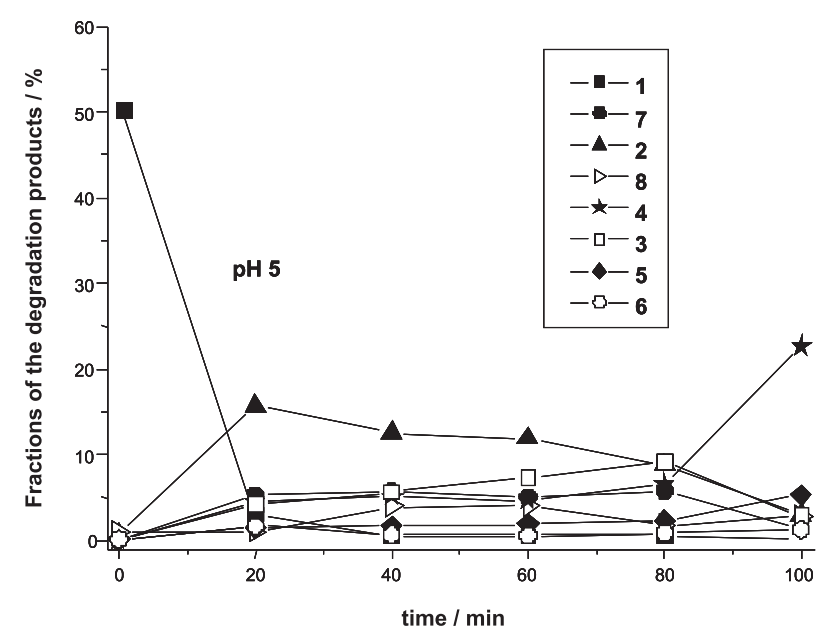

Figure 5. Fractions of the anions $[\mathbf{1}-\mathrm{H}]^{-},[2-\mathrm{H}]^{-},[3-\mathrm{H}]^{-},[4-\mathrm{H}]^{-}$, $[5-\mathrm{H}]^{-},[6-\mathrm{H}]^{-},[7-\mathrm{H}]^{-}$and $[8-\mathrm{H}]^{-}$as a function of reaction time. Each fraction was calculated as the ratio between the absolute intensity of one of such ions and the sum of the absolute intensities of the whole set of ions.

\section{pH influence}

It has been reported that at higher $\mathrm{pH}$ (basic medium) the decomposition of ozone with the formation of hydroxyl radicals is favored whereas at acidic medium ozone tends to react via 1,3 dipolar cycloaddition. Because of that, products formed in basic or acidic media are usually quite distinct. ${ }^{53,54}$ Hence, the ozonation of $\mathbf{1}$ was also conducted at $\mathrm{pH} 8$ to verify whether the products obtained would be similar to those detected at $\mathrm{pH} 5$ (as displayed in Scheme 1). The ESI(-)-MS of the aliquots withdrawn after successive reaction times are displayed in Figure 6. Note that these data revealed that the same sort of anions (with a remarkable exception: the anion $[4-\mathrm{H}]^{-}$of $m / z$ 335) 
were also detected at $\mathrm{pH} 8$. However, unlike the reaction conducted at $\mathrm{pH} 5$ for which compound 4 shown to be the predominant specie after 100 min reaction time (Figures 3 and 5), at $\mathrm{pH} 8$ the major product obtained after identical reaction time was found to be 3 . These divergent results thus seem to corroborate the expected distinct behavior that ozone can exhibit depending on the solution pH. ${ }^{53,54}$
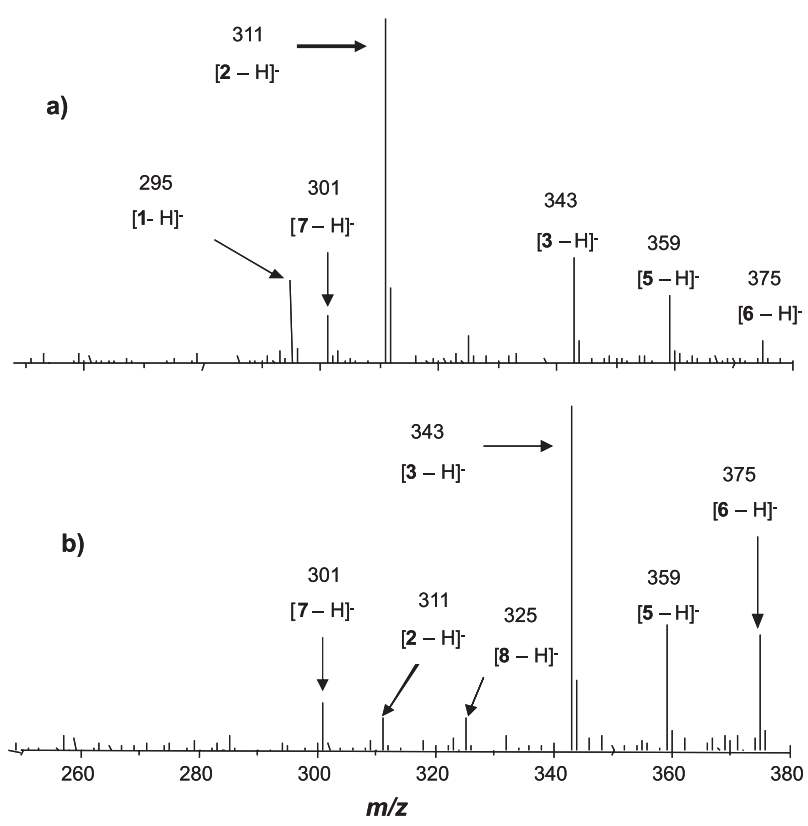

Figure 6. ESI(-)-MS monitoring of the ozonation of ethinylestradiol (1) conducted in an aqueous-methanolic medium at $\mathrm{pH} 8$ after the following reaction times: (a) $20 \mathrm{~min}$; (b) $100 \mathrm{~min}$.

\section{Conclusions}

The application of ESI(-)-MS (and MS/MS) allowed the proposition of a reaction route for the degradation of ethinylestradiol (1) by ozone in an aqueous-methanolic medium. Under the mild condition employed herein, a number of compounds (likely formed at the very beginning of the reaction process) were by the first time detected. ESI(-)-MS monitoring also allowed the attainment of relevant information regarding the influence of $\mathrm{pH}$ on the reaction course and products distribution. The results described herein seem to be complimentary to the results described in literature which show that $\mathbf{1}$ was quickly oxidized by ozone to ultimately produce small organic acids and carbon dioxide. Finally, studies have suggested that the phenolic ring of $\mathbf{1}$ is the site that bind to the estrogen receptor. ${ }^{55}$ Hence, it would be imperative to verify whether the products detected herein could have similar activity.

\section{Acknowledgments}

The authors are grateful to the Brazilian sponsor agencies, CNPq and FAPEMIG (EDT PRONEX 479/07) for the financial support.

\section{References}

1. Li, H. Q.; Song, Y. X.; Peng, X. F.; Steroids 2008, 73, 488.

2. Zhao, Y. P.; Hu, J. Y.; Jin, W.; Environ. Sci. Technol. 2008, 42, 5277.

3. Huber, M. M.; Canonica, S.; Park, G. Y.; Von Gunten, U.; Environ. Sci. Technol. 2003, 37, 1016.

4. Suri, R. P. S.; Nayak, M.; Devaiah, U.; Helmig, E.; J. Hazard. Mater. 2007, 146, 472.

5. Hansen, P. D.; Dizer, H.; Hock, B.; Marx, A.; Sherry, J.; McMaster, M.; Blaise, C.; TrAC-Trends Anal. Chem. 1998, 17, 448.

6. Hiramatsu, N.; Matsubara, T.; Fujita, T.; Sullivan, C. V.; Hara, A.; Mar. Biol. 2006, 149, 35.

7. Sole, M.; Porte, C.; Barcelo, D.; TrAC-Trends Anal. Chem. 2001, 20, 518.

8. Sumpter, J. P.; Jobling, S.; Environ. Health Perspect. 1995, 103, 173.

9. Adeoya-Osiguwa, S. A.; Markoulaki, S.; Pocock, V.; Milligan, S. R.; Fraser, L. R.; Hum. Reprod. 2003, 18, 100.

10. Deborde, M.; Rabouan, S.; Duguet, J. P.; Legube, B.; Environ. Sci. Technol. 2005, 39, 6086.

11. Lee, Y.; Escher, B. I.; Von Gunten, U.; Environ. Sci. Technol. 2008, 42, 6333.

12. Rosenfeldt, E. J.; Linden, K. G.; Environ. Sci. Technol. 2004, 38,5476

13. Rosu, F.; De Pauw, E.; Gabelica, V.; Biochimie 2008, 90, 1074.

14. Zhu, B. T.; Roy, D.; Liehr, J. G.; Endocrinology 1993, 132, 577.

15. Andersen, H.; Siegrist, H.; Halling-Sorensen, B.; Ternes, T. A.; Environ. Sci. Technol. 2003, 37, 4021.

16. Layton, A. C.; Gregory, B. W.; Seward, J. R.; Schultz, T. W.; Sayler, G. S.; Environ. Sci. Technol. 2000, 34, 3925.

17. Huber, M. M.; Gobel, A.; Joss, A.; Hermann, N.; Loffler, D.; Mcardell, C. S.; Ried, A.; Siegrist, H.; Ternes, T. A.; von Gunten, U.; Environ. Sci. Technol. 2005, 39, 4290.

18. Huber, M. M.; Ternes, T. A.; von Gunten, U.; Environ. Sci. Technol. 2004, 38, 5177.

19. Deborde, M.; Rabouan, S.; Gallard, H.; Legube, B.; Endocrinology 2004, 38, 5577.

20. Franco, D. V.; Jardim, W. F.; Boodts, J. F. C.; Da Silva, L. M.; Clean - Soil Air Water 2008, 36, 34.

21. Ternes, T. A.; Stuber, J.; Herrmann, N.; McDowell, D.; Ried, A.; Kampmann, M.; Teiser, B.; Water Res. 2003, 37, 1976.

22. Watkins, B. D.; Hengemuehle, S. M.; Person, H. L.; Yokoyama, M. T.; Masten, S. J.; Ozone-Sci. Eng. 1997, 19, 425. 
23. Liakou, S.; Kornaros, M.; Lyberatos, G.; Water Sci. Technol. 1997, 36, 155.

24. Liakou, S.; Pavlou, S.; Lyberatos, G.; Water Sci. Technol. 1997, 35, 279.

25. Fenn, J. B.; Mann, M.; Meng, C. K.; Wong, S. F.; Whitehouse, C. M.; Mass Spectrom. Rev. 1990, 9, 37.

26. Gaskell, S. J.; J. Mass Spectrom. 1997, 32, 677.

27. Chen, P.; Angew. Chem. Int. Ed. 2003, 42, 2832.

28. Hinderling, C.; Adlhart, C.; Chen, P.; Angew. Chem. Int. Ed. 1998, 37, 2685.

29. Pereira, R. M. S.; Paula, V. I.; Buffon, R.; Tomazela, D. M.; Eberlin, M. N.; Inorg. Chim. Acta 2004, 357, 2100.

30. Dalmazio, I.; Almeida, M. O.; Augusti, R.; Alves, T. M. A.; J. Am. Soc. Mass Spectrom. 2007, 18, 679.

31. Dalmazio, I.; de Urzedo, A. P. F. M.; Alves, T. M. A.; Catharino, R. R.; Eberlin, M. N.; Nascentes, C. C.; Augusti, R.; J. Mass Spectrom. 2007, 42, 1273.

32. Dalmazio, I.; Santos, L. S.; Lopes, R. P.; Eberlin, M. N.; Augusti, R.; Environ. Sci. Technol. 2005, 39, 5982.

33. de Urzedo, A. P. F. M.; Diniz, M. E. R.; Nascentes, C. C.; Catharino, R. R.; Eberlin, M. N.; Augusti, R.; J. Mass Spectrom. 2007, 42, 1319 .

34. de Urzedo, A. P. F. M.; Nascentes, C. C.; Diniz, M. E. R.; Catharino, R. R.; Eberlin, M. N.; Augusti, R.; Rapid Commun. Mass Spectrom. 2007, 21, 1893.

35. Florencio, M. H.; Pires, E.; Castro, A. L.; Nunes, M. R.; Borges, C.; Costa, F. M.; Chemosphere 2004, 55, 345.

36. Hess, T. F.; Renn, T. S.; Watts, R. J.; Paszczynski, A. J.; Analyst 2003, 128, 156.

37. Lopes, R. P.; de Urzedo, A. P. F. M.; Nascentes, C. C.; Augusti, R.; Rapid Commun. Mass Spectrom. 2008, 22, 3472.

38. Madeira, P.; Nunes, M. R.; Borges, C.; Costa, F. M. A.; Florencio, M. H.; Rapid Commun. Mass Spectrom. 2005, 19, 2015.
39. Santos, L. S.; Dalmazio, I.; Eberlin, M. N.; Claeys, M.; Augusti, R.; Rapid Commun. Mass Spectrom. 2006, 20, 2104.

40. Santos, L. S.; Knaack, L.; Metzger, J. O.; Int. J. Mass Spectrom. 2005, 246, 84.

41. Moura, F. C. C.; Araujo, M. H.; Dalmazio, I.; Alves, T. M. A.; Santos, L. S.; Eberlin, M. N.; Augusti, R.; Lago, R. M.; Rapid Commun. Mass Spectrom. 2006, 20, 1859.

42. Jardim, W. F.; Moraes, S. G.; Takiyama, M. M. K.; Water Res. 1997, 31, 1728.

43. Zhang, X.; Chen, P. Y.; Wu, F.; Deng, N. S.; Liu, J. T.; Fang, T.; J. Hazard. Mater. 2006, 133, 291.

44. Maniero, M. G.; Bila, D. M.; Dezotti, M.; Sci. Total Environ. 2008, 407, 105.

45. Yao, C. C. D.; Haag, W. R.; Water Res. 1991, 25, 761.

46. Ma, J.; Graham, N. J. D.; Water Res. 2000, 34, 3822.

47. Mvula, E.; von Sonntag, C.; Org. Biomol. Chem. 2003, 1, 1749.

48. Hoigne, J.; Bader, H.; Water Res. 1983, 17, 173.

49. Yamamoto, Y.; Niki, E.; Shiokawa, H.; Kamiya, Y.; J. Org. Chem. 1979, 44, 2137.

50. Fu, P. P.; Harvey, R. G.; Chem. Rev. 1978, 78, 317.

51. Dowideit, P.; von Sonntag, C.; Environ. Sci. Technol. 1998, 32, 1112.

52. Frauendorf, H.; Herzschuh, R.; Eur. Mass Spectrom. 1998, 4, 269.

53. Hong, P. K. A.; Zeng, Y.; Water Res. 2002, 36, 4243.

54. Konsowa, A. H.; Desalination 2003, 158, 233.

55. Hamblen, E. L.; Cronin, M. T. D.; Schultz, T. W.; Chemosphere 2003, 52, 1173.

Received: August 5, 2009

Web Release Date: January 28, 2010 